\title{
SOLAR ELECTRIC PROPULSION CARGO SPACECRAFT FOR MARS MISSIONS
}

\author{
VIRGINIA POLYTECHNIC INSTITUTE AND STATE UNIVERSITY
}

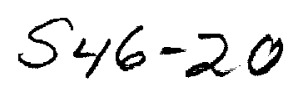

One of the topics available to the 1990/91 Aerospace Engineering senior class was the development of a preliminary design of an unmanned cargo ferry that would support the Mars mission by bringing equipment and supplies from a low Earth orbit (LEO) to a low Mars orbit (LMO).

Several previous studies initiated by NASA have indicated that low-thrust transportation systems seem to offer the best performance for Mars missions. Such systems are characterized by long spiral times during escape and capture maneuvers, high payload mass fractions, and, typically, low propellant mass fractions. Of two main low-thrust candidates, nuclear electric propulsion (NEP) and solar electric propulsion (SEP), only the first one received extensive consideration because it seemed to represent the most promising concept for a manned mission to Mars. However, any sustained Mars initiative will have to include an unmanned cargo transportation system, for which an SEP concept deserves very careful consideration.

The key assumptions and requirements established in cooperation with the Space Exploration Initiative office at the NASA Langley Research Center were

1. Vehicle is assembled at the Space Station Freedom (SSF).

2. Earth-to-orbit delivery of the vehicle components, propellant, and payload is via shuttle-C.

3. Vehicle's cargo mass is $61,000 \mathrm{~kg}$.

4. Vehicle delivers cargo to LMO at an altitude of $500 \mathrm{~km}$ and inclination of $70^{\circ}$.

5. Vehicle returns (without cargo) to SSF.

6. Vehicle should be reusable for at least three missions.

7. Vehicle is powered by ion argon thrusters.

Two configurations have been developed by two student teams, working mostly independently.

\section{FLAT SOLAR ARRAY CONFIGURATION}

The first configuration, SEMM1 (Solar Electric Mars Mission 1) uses 24 self-deployable flexible blanket solar arrays anchored to two square-bay truss beams (Fig. 1). Before the final SEMM1 design was chosen, various options were analyzed and compared with an overall goal of minimizing the total initial mass while accepting relatively long trip times (up to about three years for a round trip). Both trip time and specific impulse $\left(I_{s p}\right)$ directly affect the amount of power required, which in turn strongly influences the mass of the spacecraft. The key characteristics of the selected SEMM1 are $I_{\mathrm{sp}}$ of $8000 \mathrm{~s}$, initial power of 3.15 $\mathrm{MW}_{\mathrm{e}}$, initial thrust (near Earth) of $60 \mathrm{~N}$, and LEO to LMO trip of 654 days.

The SEMM1 solar arrays provide a total cell area of 10,370 $\mathrm{m}^{2}$ to produce $3.15 \mathrm{MW}_{\mathrm{c}}$ power near Earth. The solar cells will be of a multibandgap type, using indium phosphide (InP) as a top layer and gallium antimonide (GaSb) as a bottom cell.

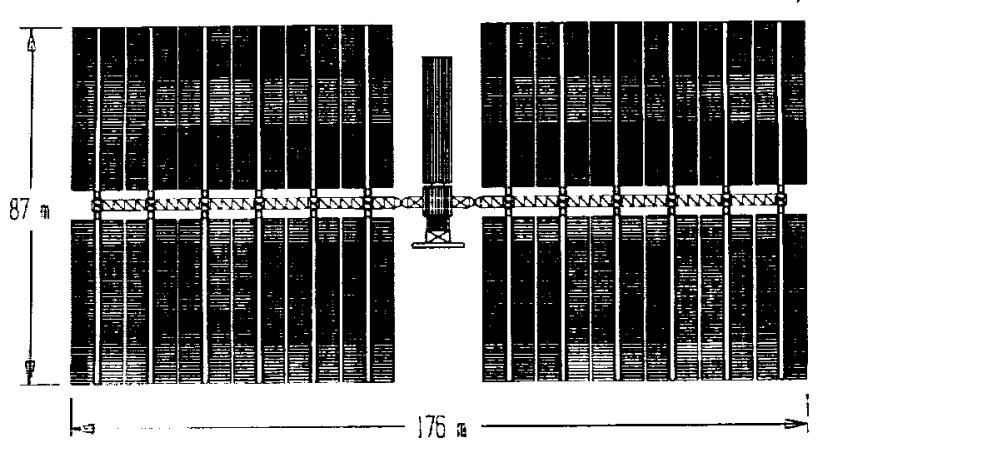

Fig. 1. Planar solar array configuration.

This combination has been studied and experimented with at Boeing and Entech. A small amount of cell output current will be drawn from the main feed to be rerun back through the cell in a forward-bias configuration to keep the cell materials above $100^{\circ} \mathrm{C}$ for self-annealing of the InP cell from the electronand proton-induced radiation damage. High potential efficiency of the cell (22.5\% InP $+8 \% \mathrm{GaSb}$ ) at air mass zero (AMO) conditions will be reduced by about $4 \%$ because GaSb cell's efficiency decreases somewhat at higher operating temperatures. Taking this into account as well as the physical and electrical losses (wiring/mismatch and forward-bias current) and the losses expected due to irreversible degradation after a long journey, the effective efficiency has been projected to be $22 \%$ throughout most of the trip to Mars, and about 2\% less after the first round trip.

The InP/GaSb cells will be arranged into arrays by using extendable flat solar panels similar to a few prototype arrays flown on the space shuttle. These prototypes were demonstrated to have adequate stiffness and deployability in a space environment. Selection of the flat panel arrays instead of those using optical concentrators was strongly influenced by three factors: in-space assembly time, launch packaging, and pointing accuracy. Extendable arrays are light-weight, do not require high pointing accuracy, are self-deployable, and are compact when stowed. Twenty-four arrays of the SEMM1 extend out from two long truss beams. The beams are attached to the sides of the ship by means of rotational $\alpha$-joints, forming two "wings," with six arrays fore and aft, on each wing. Each array consists of two solar panel blankets that are held in tension by a mast extending between them (Fig. 2). The $\alpha$-joints allow the two wings to rotate about one axis and they transmit the electrical power to the central (main) body. The mass of the solar arrays, including wiring, truss beams, and $\alpha$-joints is $15,320 \mathrm{~kg}$.

The SEMM1 propulsion system consists of 13 (including 3 redundant units) 2-m-diameter, gimbal-mounted ion thrusters, each capable of developing $6 \mathrm{~N}$ thrust at $I_{\mathrm{sp}}$ of $8000 \mathrm{~s}$. Ten 


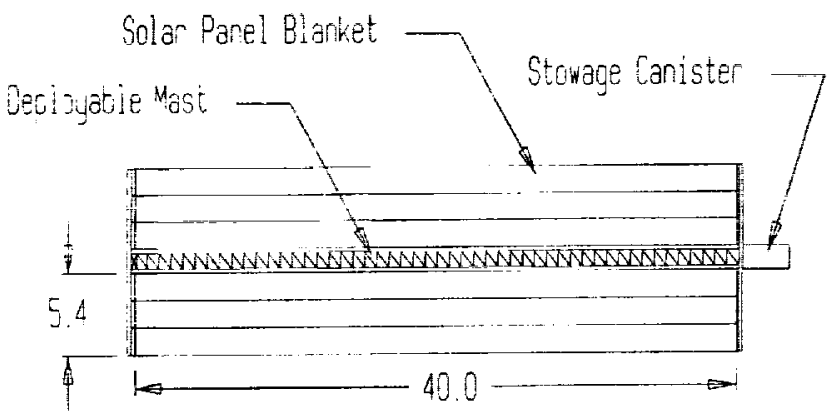

Fig. 2. Deployable solar panel blankets.

thrusters will operate during Earth-escape spiral, and four will operate near Mars. A lifetime of the thrusters is projected to be between 15,000 and 20,000 hr. High $I_{\mathrm{sp}}$ and large thruster diameter should result in a high thruster efficiency of 0.81 .

The power generated by the solar arrays must be conditioned into a form suitable for the thrusters and the onboard systems. The power processing units (PPU) supply and control the power for discharge/cathode, neutralizer, screen, and accelerator. The overall PPU efficiency is assumed to be $95 \%$, and the heat generated by the electrical components will be dissipated to space by radiators mounted on the sides of the propulsion module.

The argon propellent $(23,840 \mathrm{~kg}$ ) will be cryogenically stored at a temperature of $85 \mathrm{~K}$ in a $17.3 \mathrm{~m}^{3}$ ellipsoidal tank The tank is a two-shell type with a vapor-cooled shield surrounding it, and will be equipped with internal heaters to vaporize argon during thrusting operation, as well as with a refrigeration system to reliquefy boiled-off argon during coasting periods. An extensive meteoroid/debris protection and thermal insulation will be provided for the argon storage.

The SEMM 1 main body structure is made of graphite-epoxy box trusses that hold the thruster module, power conditioning units, auxiliary power system (batteries), navigation, guidance and communications equipment, and array orientation and vehicle control systems. The cargo container is attached to the front of the main body. Three shuttle- $C$ launches will be needed to deliver to LEO all the spacecraft components. The total initial mass of the spacecraft (at LEO) is approximately $118,000 \mathrm{~kg}$ offering a payload mass ratio of nearly $52 \%$.

\section{FRESNEL LENS CONCENTRATOR ARRAY CONFIGURATION}

The second configuration (SEMM2) uses two hexagonal shaped arrays that collect solar power by a Fresnel lens concentrator/multistacked cell system (Fig. 3). Spacecraft sizing and low-thrust trajectory analyses were aimed mainly at low total initial mass of the spacecraft and low propellant and thrusting time requirements. These considerations, combined with an assumption of high solar cell efficiency, led to a $I_{s p}$ of $10,300 \mathrm{~s}$, power requirement of around $3.5 \mathrm{MW}$, and LEO to LMO trip duration of around 960 days.

The system chosen to provide the solar power is a threesolar-cell stack proposed by Barnett and Trumble ${ }^{(1)}$ and a Fresnel lens concentrator (Figs. 4 and 5). The cell will use a six-terminal

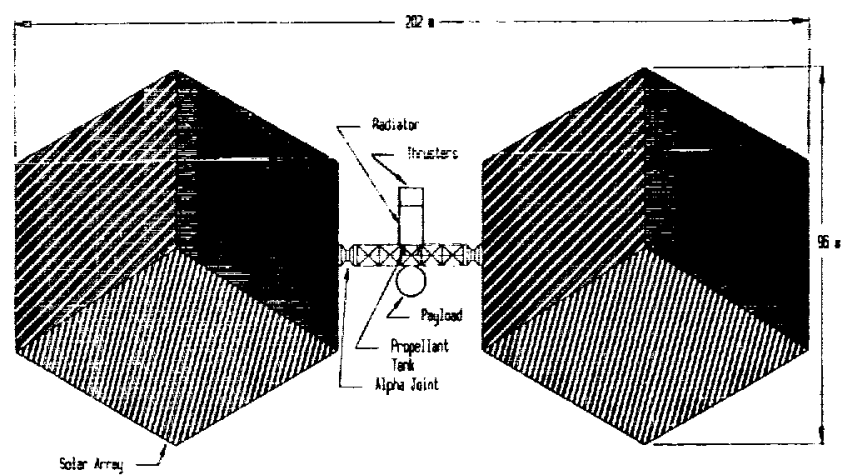

Fig. 3. Fresnel lens concentrator array configuration.

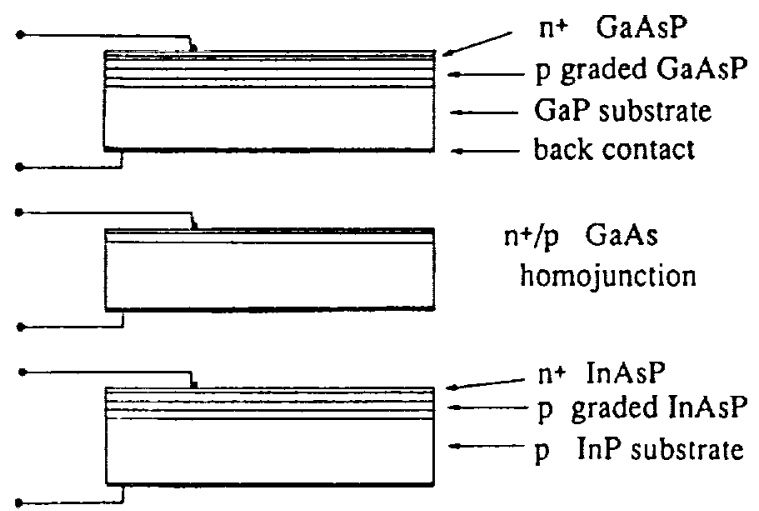

Fig. 4. Three-solar-cell stack

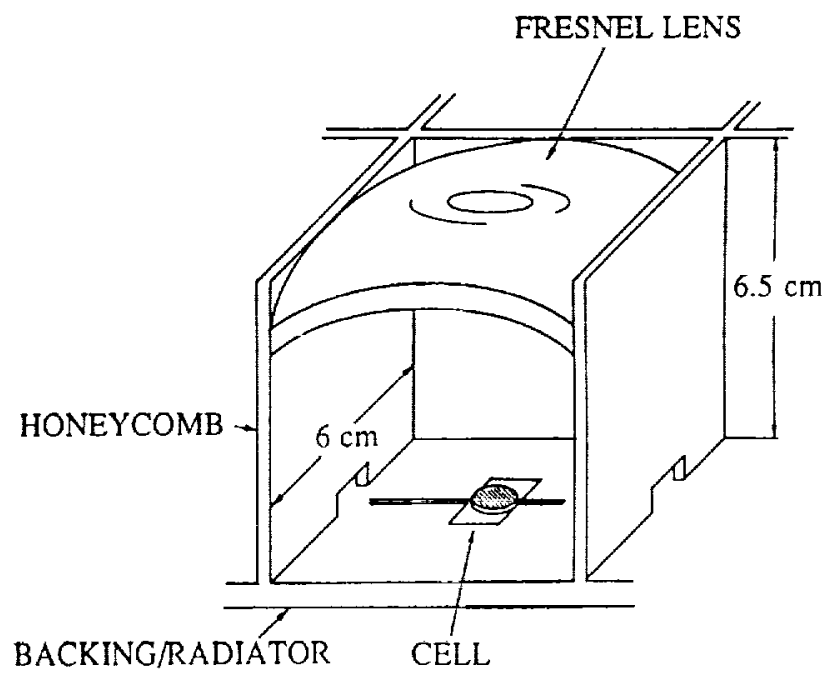

Fig. 5. Fresnel lens module. 
wiring configuration to minimize current mismatch losses that may be caused by different degrees of radiation damage to the three solar cells. The GaAsP-on-GaP top cell, which determines the performance of the triple stack, is the most advanced widebandgap cell currently under development. The state-of-the-art GaAs cell will serve as the middle cell. The InAsP bottom cell is least developed and even when "immature" can only improve the total conversion efficiency by scavenging the low-energy photons from the top two cells. A theoretical efficiency limit of this triple solar cell stack is $\mathbf{4 2 . 8 \%}$ at AMO and a practical system efficiency of $35.9 \%$ is predicted ${ }^{(1)}$. In application to our spacecraft, an efficiency of $27 \%$ was assumed to account for the high operating temperature of about $150^{\circ} \mathrm{C}$ and the radiation damage occurring during the three Mars missions.

The array is made up of small modules, $6 \mathrm{~cm}$ on each side and $6.48 \mathrm{~cm}$ high (Fig. 5). Each module consists of a Fresnel lens dome that concentrates the incident sunlight on the 6-mm-diameter cell, a honeycomb supporting structure, a multistacked cell, and a back radiator panel to dissipate excess heat. Each lightweight silicone Fresnel lens has a thin protective diamond film coating on the upper surface of the lens. The thin-wall honeycomb structure is made of graphite-epoxy with a protective coating. This structure provides a simple way to create a rigid array with less weight penalty than other array systems. The array is designed to allow a maximum deflection of $2^{\circ}$. A wall height of $6.48 \mathrm{~cm}$ was chosen as a compromise between strength, low mass, and shuttle-C space requirements. The array wiring is designed to minimize both the weight and the power loss.

Solar array support structure is designed to be resistant to out-of-plane deformations and vibrations. It is constructed of three concentric "rings" of tetrahedral pyramid-shaped elements. Each element is assembled from six half-conical strut members made of anodized-aluminum-coated graphite epoxy. The total mass of the solar arrays, without $\alpha$-joints and trusses connecting to the main body, is about $13,000 \mathrm{~kg}$.

The electric propulsion system consists of 17 ion engines including 5 redundant units. Twelve engines will operate near Earth producing a maximum thrust of $60 \mathrm{~N}$. Each engine has a beam diameter of $130 \mathrm{~cm}$ and its beam power, discharge power, and neutralizer power are $252.6,20.8$, and $1.7 \mathrm{~kW}$, respectively. To provide a lifetime of 20,000 to $25,000 \mathrm{hr}$, a ring-cusp magnetic configuration and a moderate beam current density are selected; it is also possible to add a small amount of nitrogen to the discharge chamber. The engine efficiency is assumed to be 0.714 and the power processing efficiency is 0.95 . The total mass of the propulsion system is $9140 \mathrm{~kg}$.

The argon propellant mass of $24,200 \mathrm{~kg}$ is stored cryogenically in a cylindrical tank ( $2.6 \mathrm{~m}$ diameter, $4.1 \mathrm{~m}$ length) with hemispherical end caps. The tankage mass, including protective shield/insulation, electrical heaters, Stirling refrigeration unit, propellant lines, valves, and controls, is $820 \mathrm{~kg}$.

The central supporting structure of the ship uses orthogonal tetrahedral truss cells. The mass of this structure including engine mounts, cargo bay, and rotational $\alpha$-joints is estimated at $\mathbf{3 6 0 0}$ $\mathrm{kg}$. The attitude/orientation control system of the ship and solar array is based on the control moment gyroscopes (CMG) and small electric thrusters. The communications and navigation systems employ 6 antennas ( 2 high gain and 4 omnidirectional;
Ka- and X-band), transponders, command data, and handling subsystems based on low-power 32-bit processors, and navigation subsystem based on 3 star trackers, 3 dry inertial measurement units, and 11 solar sensors.

Earth-to-LEO delivery of the ship components, propellant, and payload will require three shuttle-C launches. The total initial mass of the spacecraft is approximately $116,000 \mathrm{~kg}$, resulting in a payload mass ratio of nearly $53 \%$.

\section{CONCLUSIONS}

An SEP cargo spacecraft using high $\mathrm{I}_{\mathrm{sp}}$ and either planar or concentrator arrays offers a very high payload mass fraction (around 52\%) and a low initial mass of the system. Implementation of the SEP system will require a significant advance in solar cell technology and a further development of large ion thrusters. If the pace of the progress in solar cell technology made over the past 10 years is sustained, we may expect that during the next 15-18 years efficiencies and resistance to radiation damage can be increased to and beyond the levels assumed in our studies, i.e., AMO efficiencies of $22 \%$ and $27 \%$ for the planar and concentrator arrays, respectively. In laboratory tests, planar InP cells have attained a value of $18.8 \% \mathrm{AMO}$, and GaAs concentrator cells exceeded $22 \%$. Both types have shown potential to be highly resistant to the natural radiation environment. Incorporation of new developments in surface passivation, front surface shaping, and dot junction geometry may result in concentrator GaAs efficiencies approaching $\mathbf{2 8 \%}$ at concentrations of around 100 . Supperlattice solar cells (comprising layers of different semiconductor materials) and tandem cells currently under development in several laboratories and proposed for our vehicles, offer a further significant improvement in cell performance. Because the bulk recombination losses can be drastically reduced in such cells, very high collection efficiencies are possible. In addition, an increased lifetime of minority carrier should result in a very high resistance to radiation damage and, thus, in a significant extension of the lifetime of solar cells. As far as ion engine life is concerned, there are no inherent or strong reasons why the lifetimes of high-power, large-diameter ion engines should not be comparable to those of the current engines and subject to further improvement so as to reach $15,000-25,000 \mathrm{hr}$.

We anticipate that high-performance/long-lifetime solar cells will become available for space applications by 2005-2010, and at that time SEP propulsion system will be highly competitive if not superior to nuclear electric propulsion (NEP), because it is likely to offer a higher payload fraction, no environmental concerns, and lower launch and assembly costs. The increased NEP costs are associated with an initial safe Earth orbit higher than LEO.

\section{ACKNOWLEDGMENTS}

SEMM1 design team members were C. E. Callaghan, M. D. Crowe, M. R. Mickney, C. K. Montgomery, M. J. Swis, S. Thoden, and R. Walters. SEMM2 team members were A. Chiles, J. Fraser, 
A. Halsey, D. Honeycutt, B. Mc Gough, D. Paulsen, B. Spear, L. Tarkenton, and K. Westley. Project advisors were Dr. A. K. Jakubowski (VPISU) and D. A. Haynes (NASA Langley Research Center)

\section{REFERENCES}

1. A. M. Barnett, T. M. Trumble, G. H. Negley, S. L. Rhoads, J. B. McNeely, and N. E. Terranova, "A Three-Solar-Cell Mechanically Stacked, Multijunction System With Energy Conversion Efficiencies Greater

Than 30\% AMO," 22nd IECEC Conference, Vol. 1, Aug. 1987. 